\title{
Embedding ethics in nanomedicine: Europe acted promptly
}

\section{Preamble}

The Oxford Dictionary defines nanotechnology as "the branch of technology that deals with dimensions and tolerances of less than 100 nanometres, especially the manipulation of individual atoms and molecules."1 Nanotechnology has application in multiple scientific fields, such as surface science, organic chemistry, molecular biology, semiconductor physics, energy storage, microfabrication, and molecular engineering. It is a technology capable of creating new materials and devices with a potential vast range of applications, such as in medicine (hence, the term "nanomedicine"), electronics (hence, "nanoelectronics"), biomaterial energy production, and consumer products. As innovative technologies often do, however, nanotechnology applications have raised an intense debate in the circles of scientists, lawyers, and policymakers, including on ethical issues.

In the early 2000s, controversies emerged regarding the definitions and potential implications of nanotechnology, including the safety (for health and/or the environment) of the very first products originating from nanotechnology such as silver nanoparticles, carbon fiber strengthening using silica nanoparticles, and carbon nanotubes. In particular, nanomedicine has acquired a progressive importance on the societal debate on the ethical dimension of this technology and the expectations and concerns on its use.

\section{Nanomedicine: What is possible to do?}

A European technology platform on nanomedicine has been created and in 2005 issued its first vision paper. ${ }^{2}$ Its activities included diagnosis, drug delivery, and triggering of biomaterials. This activity in nanomedicine is continuing. ${ }^{3}$ With no

$1 \mathrm{https} / / /$ www.lexico.com/definition/nanotechnology.

2 http://ec.europa.eu/research/industrial_technologies/pdf/nanomedicine-visionpaper_en.pdf.

$3 \mathrm{https} / / /$ etp-nanomedicine.eu/.

Disclaimer: The information and views set out in this chapter are those of the authors and do not necessarily reflect the official opinion of the European Commission.

Renzo Tomellini, Head of Unit “Science Policy, Advice and Ethics", European Commission, Brussels, Belgium

Maurizio Salvi, Unit “Science Policy, Advice and Ethics”, European Commission, Brussels, Belgium 
pretention of completeness, some applications of nanotechnology in the medical fields include: ${ }^{4}$

\begin{tabular}{ll}
\hline Application area & Expected benefits \\
\hline Drug delivery & $\begin{array}{l}\text { Nanotechnology provided the possibility of delivering drugs to specific cells } \\
\text { using nanoparticles. }\end{array}$ \\
\hline Cancer & Nanoparticles can be used against tumor cells and accumulate at tumor sites. \\
\hline Imaging & $\begin{array}{l}\text { Nanoparticles may be used for in vivo imaging (cardiovascular imaging or } \\
\text { oncology imaging). }\end{array}$ \\
\hline Sensing & $\begin{array}{l}\text { Research on nanoelectronics could lead to tests for the diagnosis and treatment } \\
\text { of cancer. }\end{array}$ \\
\hline Blood & $\begin{array}{l}\text { Magnetic microparticles are research instruments for the treatment of systemic } \\
\text { purification }\end{array}$ \\
$\begin{array}{l}\text { infections, and they may also provide alternatives to traditional dialysis } \\
\text { methods. }\end{array}$ \\
\hline Tissue \\
engineering & $\begin{array}{l}\text { Nanotechnology may be used to reproduce, repair, or reshape damaged tissue } \\
\text { using suitable nanomaterial-based scaffolds. }\end{array}$ \\
\hline Medical devices & $\begin{array}{l}\text { Nanoscale enzymatic biofuel cells for nanodevices have been developed that } \\
\text { uses glucose from biofluids including human blood and watermelons. }\end{array}$ \\
\hline
\end{tabular}

In addition to this set of current applications of nanomedicine, the community of scientists has also advocated the possibility of engineering molecular assemblers (hence, the term "nano-robots"), which could reorder matter at a molecular or atomic scale and then be implanted into the systems or organisms, including the human body, to repair or detect damages and infections.

\section{The safety issues}

Because nanomedicine may affect citizens, both directly (trials) and indirectly (possible exposure to free nanoparticles into the environment), it is important to underline the safety of this technology in order to protect their rights and their aspirations. A central consideration in assessing the legitimacy of medical technologies therefore refers to their safety. ${ }^{6}$

4 See also https://www.britannica.com/science/nanomedicine.

5 Nanoparticles such as graphene, carbon nanotubes, molybdenum disulfide, and tungsten disulfide are being used as reinforcing agents to fabricate mechanically strong biodegradable polymeric nanocomposites for bone tissue engineering applications.

6 However, even if it is hard to define a precise borderline between the two dimensions, a distinction needs to be done between risks for the patients undergoing an application of nanomedicine and risks associated with the toxicological and ecotoxicological effects of nanocomponents. 
Safety issues of nanotechnology and nanomedicine have been addressed in several reports across the world. The Scientific Committee on Emerging and Newly Identified Health Risks ${ }^{7}$ (SCENIHR) report and the White Paper Nanotechnology Risk Governance $^{8}$ published in June 2006 by the International Risk Governance Council are two examples of reports on risk governance issues of nanotechnology. While using different approaches and methods, the above reports stress the lack of data (in particular, long-term data) on possible risks associated with nanotechnology with regard to both the human health and the ecological consequences of nanoparticles accumulating in the environment. In addition (to quote the UNESCO report on the ethics and politics of nanotechnology ${ }^{9}$ ), the issue of the safe and responsible use of nanomedicine and nanotechnology raises "two concerns: the hazardousness of nanoparticles and the exposure risk. The first concerns the biological and chemical effects of nanoparticles on human bodies or natural ecosystems; the second concerns the issue of leakage, spillage, circulation, and concentration of nanoparticles that would cause a hazard to bodies or ecosystems." Concerns are also raised by the difficulties of identifying, estimating, and managing risks in an area where there are considerable uncertainties and knowledge gaps, and when the short-term and long-term risks may be different.

\section{The existing framework on ethics and human rights}

While the above considerations show the difficulty to assess the safety of biomedical products, it is important to refer to the existing framework on ethics and human rights that constitutes a reference point for the analysis of the ethical dimension of nanotechnology. Let us then consider some international references having a legal or moral authority in this analysis (soft and hard law).

(a) The Council of Europe has issued the Oviedo Convention - Convention on Human Rights and Biomedicine. ${ }^{10}$ Its main purpose is to "preserve human dignity, rights and freedoms, through a series of principles and prohibitions against the misuse of biological and medical advances.” The convention also concerns equitable access to health care, professional standards, protection of genetic heritage, and scientific research. It contains several detailed provisions on informed consent. A number of additional protocols supplement the convention. ${ }^{11}$

\footnotetext{
7 Scientific Committee on Emerging and Newly Identified Health Risks (SCENIHR).

8 See the White Paper Nanotechnology Risk Governance published in June 2006 by the International Risk Governance Council and the references in that report.

9 http://unesdoc.unesco.org/images/0014/001459/145951e.pdf.

$10 \mathrm{https} / /$ www.coe.int/en/web/bioethics/oviedo-convention.

$11 \mathrm{http}: / /$ www.coe.int/t/e/legal_affairs/legal_cooperation/bioethics/texts_and_documents/1Trea ties_COE.asp\#TopOfPage.
} 
(b) The Universal Declaration on the Human Genome and Human Rights, ${ }^{12}$ adopted by UNESCO's General Conference in 1997 and subsequently endorsed by the United Nations General Assembly in 1998, deals with the human genome and human rights. Since the Declaration was drafted in 1997, it does not refer explicitly to nanomedicine, but modifications that are targeted to DNA may fall within its scope. ${ }^{13}$ The Declaration also contains provisions on the informed consent principle. The Universal Declaration on Bioethics and Human Rights (adopted by UNESCO on 19 October 2005) also contains specific provisions on ethical issues related to medicine, life sciences, and associated technologies, and advocates several ethical principles, including human dignity, consent, autonomy and responsibility, privacy, equity and justice, solidarity, and benefit sharing. ${ }^{14}$

(c) The European Charter of Fundamental Rights ${ }^{15}$ emphasizes that the Union is founded on the indivisible and universal values of human dignity, freedom, equality, and solidarity and on the principles of democracy and the rule of law. It contributes to the preservation of these common values while respecting the diversity of the cultures and traditions of the peoples of Europe, as well as the national identities of the Member States and the organization of their public authorities. The Charter formulates a common set of basic shared values at the EU level. ${ }^{16} \mathrm{Re}$ spect for human dignity, a ban on human reproductive cloning, respect for people's autonomy, non-commercialization of biological components derived from the human body, prohibition of eugenic practices, protection of people's privacy, and freedom of science: these are examples of values enshrined in the Charter, which was adopted at the Summit of Nice in 2001.

(d) The precautionary principle: according to the Commission Communication of February 2000 , the basic constituents of the precautionary principle and the prerequisites for its application are the existence of a risk, the possibility of harm, and scientific uncertainty concerning the actual occurrence of this harm. ${ }^{17}$ Although

12 https://en.unesco.org/themes/ethics-science-and-technology/human-genome-and-humanrights.

13 The Declaration asserts, "Dignity makes it imperative not to reduce individuals to their genetic characteristics and to respect their uniqueness and diversity."

14 http://portal.unesco.org/shs/en/file_download.php/46133e1f4691e4c6e57566763d474a4dBioe thicsDeclaration_EN.pdf.

15 Approved on 28 September 2000 and proclaimed by the European Parliament, the Council and the Commission on 7 December 2000.

16 For example, Article 1 (respect for human dignity), Article 3 (ban on human reproductive cloning, respect for people's autonomy, non-commercialization of biological components derived from the human body, prohibition of eugenic practices), Article 8 (data protection issues), Article 13 (freedom of science).

17 The precautionary principle does not necessitate impassable boundaries or downright bans. It is a general risk management tool, which was originally restricted to environmental matters. In the Commission's Communication of February 2000, it is stated, “The precautionary principle is not 
this principle is not explicitly mentioned in the treaty except in the environmental field, its scope is far wider and covers those specific circumstances where scientific evidence is insufficient, inconclusive, or uncertain and there are indications through preliminary objective scientific evaluation that there are reasonable grounds for concern that the potentially dangerous effects on the environment, human, animal, or plant health may be inconsistent with the chosen level of protection. ${ }^{18}$

(e) The innovation principle, as understood and applied by the Commission, ${ }^{19}$ promotes smart and future-oriented regulation that is able to encourage new discoveries and solutions to address the most pressing social and environmental issues.

\section{Bioethical questions}

In its opinion on ethics of nanomedicine, the European Group of Ethics ${ }^{20}$ has indicated a list of concerns that need to be faced to assess the ethics of this technological sector, such as "How is it possible to give information about future research possibilities in a rapidly developing research area and to make a realistic risk assessment in view of the many unknowns and the complexities? What are the implications of nanomedicine for problems raised in cases where the information obtained by refined nanomedical diagnostic methods is used by third parties, in particular, insurance companies and employers? How can the development of nanomedicine and nanotechnology be tailored to the benefit of the public? How can societies remain at least partly autonomous in their decisions, when the development of nanomedicine is closely connected to the economic prosperity of a given society and plays a part in international competition on the global market?"

defined in the Treaty, which prescribes it only once - to protect the environment. But in practice, its scope is much wider, and specifically where preliminary objective scientific evaluation indicates that there are reasonable grounds for concern that the potentially dangerous effects on the environment, human, animal or plant health may be inconsistent with the high level of protection chosen for the Community" (Communication Summary paragraph 3). Accordingly, the Commission believes that "the precautionary principle is a general one" (i.e., a general principle) (Section 3 of the Communication), whose scope goes beyond the EU - as shown by several international instruments starting with the Declaration on Environment and Development adopted in Rio de Janeiro in 1992.

$18 \mathrm{https}$ ://eur-lex.europa.eu/legal-content/EN/TXT/PDF/?uri=CELEX:52000DC0001\&from=EN.

$19 \mathrm{https} / /$ ec.europa.eu/info/news/innovation-principle-makes-eu-laws-smarter-and-future-ori ented-experts-say-2019-nov-25_en.

20 Group of Ethics examined the ethical aspects of medical applications related to nanotechnology. Some of the basic ethical values include the principle of respect for dignity; the principle of individual autonomy; the principle of justice and of beneficence; the principle of freedom of research; and the principle of proportionality. https://op.europa.eu/en/publication-detail/-/publication/ 4d7d9c99-2129-42e1-993e-c815b91f256b/language-en/format-PDF/source-77404425, pp. 39-41. 
The above questions relate to the ethical dimension of nanomedicine. As other technological mediums they do not induce univocal response, but they refer to a number of values/principles that need to be assessed with regard to each different use of nanomedicine is concerned. Case-by-case analyses are therefore inherent to the ethics of nanomedicine, also reflecting the ethical pluralism of modern society. In whatever views we therefore want to focus the ethical analysis of nanomedicine, whether following utilitarianism, Kantianism, virtue theory, the principles of autonomy, beneficence, non-maleficence, and justice, it is important that specific elements that are embodied in the international ethics frame described earlier are taken into account.

The protection offered by international declarations and guidelines applies to both health care and medical research; it includes the obligation to obtain free and informed consent from patients and participants in research and specifies the measures to be taken when patients and participants in research are for various reasons (minors, mentally incapacitated, etc.) unable to give consent. The principles stated in the above declarations and guidelines specify the obligations to protect individuals and societies against unpredictable risks based on the precautionary principle and a risk-benefit analysis, which includes also long-term risks and benefits. The principles mentioned earlier are also applied to health-related risks of nanotechnology, not only in the medical contexts, which are in focus here, but also in other contexts where nanotechnology is used. To summarize, the bioethics issue of nanomedicine that deserve specific attention include:

\section{- Informed consent}

Informed consent requires the information to be understood. In view of the knowledge gaps, and the complexity of the matter, concerning the long-term effects of nanomedical diagnostic and therapeutic tools, it may be difficult to provide adequate information concerning a proposed diagnosis, prevention and therapy needed for informed consent.

- Diagnostic complexity and increased personal responsibility

Nanomedicine offers new diagnostic possibilities, where the results will be available with high speed, magnitude, and precision at the molecular level. The results may be complex and difficult to interpret. The increased complexity of diagnostic potentials affects the level of responsibility by the medical community to properly interpret diagnostic results and propose therapeutic actions based on the above provisions.

\section{- Medical and non-medical uses}

The fine line between medical and non-medical uses of nanomedical methods for diagnostic, therapeutic, and preventive purposes is often hard to define, but it is possible to give examples of both. Non-medical applications include intentional changes in, or to, the body due to what a person wants, when these wants are not related to medical needs, even if such medical needs are difficult to define clearly. 


\section{- Access from an individual perspective}

Access to health care and new medical technologies is often seen as a challenge for health-care systems and then opening issues related to fairness. Individuals may struggle to gain access to nanomedical innovations, even taking on considerable financial costs. If they cannot afford new diagnostics, drugs, or therapies offered to them, they might feel left behind or even as second-class citizen.

As stated before, what is described here is a non-exhaustive frame of reference points that need to be confronted with the specific applications of nanomedicine. This method applies to case-by-case analyses and aims to reflect the ethical pluralism of modern society.

In the next part of this chapter, we describe how the approach chosen in the EU intrinsically links ethical considerations (both individual and social ethics) into the policy frame of nanomedicine and nanotechnology.

\section{Embedding ethics in nanomedicine: The policy frame adopted in the EU}

When this technology was developed, the European Commission had to face its controversy, not only in terms of public acceptance but also in terms of safety and in terms of adequacy of regulatory frame for nanotechnology-based products. Differently than other technology, items the Commission decided to anticipate the debate on both the safety and social acceptability of this medium and the risk management approach were built in terms of an unprecedented transparency, inclusiveness, and anticipatory nature. ${ }^{21}$ In its strategic document on nanosciences and nanotechnology, the Commission indicated that nanotechnology products must comply with the high levels of consumer, worker, and environmental protection set in Community regulations. ${ }^{22}$ In June 2008, the Commission adopted the Communication "Regulatory Aspects of Nanomaterials,"23 fulfilling a commitment made in the Action Plan. ${ }^{24}$ The Communication was accompanied by a Staff Working Document providing a summary of legislation in relation to health, safety, and environmental aspects of nanomaterials, and outlining regulatory research needs and related measures. ${ }^{25}$ This regulatory review concluded that existing Community regulatory frameworks cover in principle the potential health, safety and

21 https://ec.europa.eu/research/industrial_technologies/pdf/policy/action_plan_brochure_en.pdf $22 \mathrm{https} / / /$ www.europarl.europa.eu/registre/docs_autres_institutions/commission_europeenne/ com/2009/0607/COM_COM(2009)0607_EN.pdf.

23 Regulatory Aspects of Nanomaterials, COM(2008)366.

24 https://ec.europa.eu/research/industrial_technologies/pdf/policy/action_plan_brochure_en. pdf.

$25 \operatorname{SEC}(2008) 2036$. 
environmental risks related to nanomaterials. Without excluding regulatory change in the light of new information, the Commission stressed that the protection of health, safety, and the environment needed to be enhanced mainly by improving the implementation of existing legislation. In addition to supporting research on risk assessment, the Commission has worked in several regulatory areas to improve implementation, assess the adequacy of existing legislation, and consider whether regulatory changes on specific aspects were necessary. ${ }^{26}$

The above Communication was examined by both the European Parliament ${ }^{27}$ and the European Economic and Social Committee. ${ }^{28}$ The European Parliament in particular questioned whether, in the absence of explicit provisions for nanotechnology in Community law, legislation can be deemed adequate to cover the risks related to nanomaterials. Given the lack of appropriate data and assessment methods, the Parliament asked that existing regulations be carefully reviewed (not only nanomedicine but also the use of nanotechnology in cosmetics, novel food, and food additives). As planned, the Commission presented an updated regulatory review in 2011, paying particular attention to the points raised by the European Parliament and the European Economic and Social Committee.

The Commission has therefore supported innovation in nanotechnology through different policies and actions. The main initiatives related to nanotechnology included increased emphasis on applications in the research funded under the research and innovation framework programs; a continued commitment to regulatory and standardization activities; and the creation of a nanotechnology observatory, ObservatoryNANO, ${ }^{29}$ to study opportunities and risks in various technology sectors. In this context, special attention was also paid to SMEs and start-ups.

Several actions were equally undertaken in pursuit of the general objective of taking people's expectations and concerns into account. In February 2008, the Commission adopted the recommendation for a "Code of Conduct for responsible nanosciences and nanotechnologies research," 30 which provides guidelines favoring a responsible and open approach. As called for by the Council in September 2008, ${ }^{31}$ the Commission regularly monitor the Code, and revise it every two years in order to take into account developments in nanotechnology and their integration in European society.

All research project proposals that were considered for funding (by the European Commission) and raising ethical issues underwent a thorough ethical review. This

26 For example, the working group for nanomaterials under REACH has made progress and published initial results: http://ec.europa.eu/environment/chemicals/reach/pdf/nanomaterials.pdf.

27 Resolution of 24 April 2009 on regulatory aspects of nanomaterials (2008/2208(INI)).

28 Opinion of 25 February 2009 on the Communication on Regulatory Aspects of Nanomaterials, INT/456; http://eesc.europa.eu/documents/opinions/avis_en.asp?type=en.

29 www.observatorynano.eu.

30 Code of Conduct for Responsible Nanosciences and Nanotechnologies Research, C(2008)424.

31 12959/1/08 REV 1 (2891st Council Meeting Competitiveness). 
included many nanotechnology proposals. Such proposals had discussed the ethical dimension of the research to be undertaken and meet community ethical requirements, such as the EU Charter of Fundamental Rights, in addition to national requirements.

Several outreach projects have been funded under the European Commission research programs. These suggest that there is a need for a more permanent public deliberation on nanotechnology in its broad societal context. The Commission has pursued an active policy of engagement and consultation with stakeholders, in particular through their continuous involvement in Commission working groups in charge of coordinating the implementation of regulation; and in the annual nanotechnology "Safety for Success Dialogue" workshops. The call for dialogue and engagement in the action plan has also been reflected in various other initiatives organized by industry, in European Technology Platforms, and in special interest forums such as consumers' groups. The existence of diverse fora indicates a need to monitor the debates at national, European, and international levels, for instance, with support from future European Commission activities, in order to consistently convey messages from public debates to policymakers. The Commission has also published a wide range of informative materials in many languages and for various age groups. In addition, a specific entry for nanotechnology on the Commission's Europa website has helped the public to follow all its nanotechnology activities.

As far as the science for policy aspects of this example are concerned, what it was relevant from the Commission was not only to address the scientific assessment of the nanotechnology products in specific application domains (e.g. medicine and food SCENIHR), but to ask the European Group on Ethics to assess the governance aspects of this technology. This request was done at European Commission's top level (President of the Commission) and aimed to analyze this technological sector under the remit of this independent advisory body: issuing a set of policy recommendations based on the scientific, legal, social, and ethical implications that may rise from the use of nanotechnology. This work was also done in consultation of key experts in the field, decision-makers, and relevant stakeholders. ${ }^{32}$ In addition, a coordination group (ISG/Inter Services Group) clustering 20 commission services was established to check the consistency of actions taken by different Commission Directorates in this specific field. The strategic choice by the Commission was to have scientific advice not only on technical aspects of nanotechnology but also on a strategy to endorse for a transparent, inclusive, responsible, and socially acceptable use of this technology and the products based on its use. In fact, this strategy has showed being successful, and nanotech-based products are part of many innovative industrial productions across the EU.

32 https://ec.europa.eu/archives/bepa/european-group-ethics/archive-activities/activities-20052010/index_en.htm and https://ec.europa.eu/archives/european_group_ethics/archive/2005_2010/ activities/docs/roundt_nano_21march2006_final_en.pdf. 


\section{Conclusions}

Pluralism is a characteristic of the European Union, ${ }^{33}$ mirroring the richness of its traditions and adding the need for mutual respect and tolerance. Respect for different philosophical, ethical/moral, or legal approaches and for diverse cultures is implicit in the ethical dimension of building a democratic Europe. Social and ethical pluralism requires that a culture of debate and communication needs to be established wherever and whenever wide-ranging changes to the lives of individuals, or in social practices, take place or are liable to take place in the future.

The above is relevant also for the controversies prompted by nanomedicine. Such issues have been addressed upfront in Europe, both in the European Commission Communication "Towards a European Strategy for Nanotechnology" ${ }^{34}$ and stimulating international cooperation such as with the workshop "Nanotechnology: Revolutionary Opportunities \& Societal Implications” co-organized with the US National Science Foundation ${ }^{35}$ and launching an open "International Dialogue on Responsible Research and Development of Nanotechnology."36

The mentioned European strategy spelled clearly out how ethical principles must be respected and, where appropriate, enforced through regulation. These principles are embodied in the European Charter of Fundamental Rights ${ }^{37}$ and other European and international documents. ${ }^{38}$ The EU has, furthermore, taken several steps in the development of policy design of nanomedicine within the constraints of the principle of respect for the rights of individuals, respect for multiculturalism, dialogue, and tolerance. The proposed approach did not try to fix ethics rules for nanomedicine, but rather stimulate a flexible approach to the governance of nanomedicine, where ethical evaluation, safety, legal clarification (including data protections and patenting), and social debate were all equally requested for the design and use of nanomedical application and research in nanomedicine.

Renzo Tomellini and Maurizio Salvi

33 Respect for pluralism is in line with Article 22 of the European Charter of Fundamental Rights, on "Cultural, religious and linguistic diversity" and with Article 6 of the Amsterdam Treaty, which ensures the protection of fundamental rights at EU level, based in particular on international instruments as well as common constitutional traditions, while also stressing respect for the national identity of all Member States.

34 https://ec.europa.eu/research/industrial_technologies/pdf/policy/nano_com_en_new.pdf.

35 https://www.nsf.gov/mps/dmr/lecce_workshop.pdf.

36 https://ec.europa.eu/research/industrial_technologies/pdf/policy/report-third-international-dia logue-2008_en.pdf.

37 See http://www.europarl.eu.int/charter/default_en.htm.

38 See http://europa.eu.int/comm/research/science-society/ethics/legislation_en.html. 